\title{
Obituary
}

\section{HARRY MILTON MARKS}

1947-2011

On 24 January 2011, Harry Milton Marks, the A. McGehee Harvey and Elizabeth Treide Harvey Associate Professor in the History of Medicine, Institute of the History of Medicine, Johns Hopkins University, died in Baltimore at the age of sixty-four. Colleagues, friends, and family have much to mourn personally by the passing of a warm, intensely memorable person who was carried away before his time. In addition, the field of the history of medicine has suffered a terrible loss.

We knew Harry as the conscience of history of medicine scholarship. In personal communications, at meetings, in print, in peer-review documents, and as founding editor of H-SCI-MED-TECH < http://www.h-net.org/ smt/> from 1996 to 2000, he encouraged, instructed, and corrected people in the field - the young, the seniors, and anyone else. Did you miss an obvious source? Why were you not doing a proper and thorough literature search? Did your interpretation get ahead of your evidence? Better stick close to available documentation and read sources carefully. Does your work have connections and ramifications in the social sciences? Better be much more broadly read in current and past theories and findings. Does your work betray a bias? Understand what that bias means. Altogether Harry served as the lively, genial public superego of historians of medicine - and often in associated fields as well, for he treated medicine as part of science and economics and also as a policy driver.

Harry trained to become an historian, at Hofstra and Wisconsin, but he then worked in research and consulting in policy areas before he took his $\mathrm{PhD}$ in political science at MIT in 1987 and began his association with Johns Hopkins. He never lost touch with people who were actually carrying out social policy, and he held adjunct appointments in epidemiology and anthropology. What made him so valuable to others was not just his quality of mind but his ability to frame questions in broad theoretical and also practical terms. If you did not see the implications of your own work, Harry would gladly call them to your attention. His support of young scholars was legendary.

Perhaps because he knew so many fields so well, Harry had an admirable professional detachment, a detachment that he used to explore viewpoints from both the past and the present. His classic book, The Progress of Experiment: Science and Therapeutic Reform in the United States, 1900-1990 (Cambridge: Cambridge University Press, 1997), exemplifies the breadth of his understanding and his ability to describe the past in hard-headed terms. He tells how we came to randomised clinical trials, exposing how both aspirations and human shortcomings worked out in the area between science and bedside medicine. His nuanced, troubling story is indeed cited very, very widely, especially in an era of evidence-based medicine - but sometimes, as Harry pointed out privately, by scholars who appear not to have read or at least not to have understood the book.

After Harry learned that he was fatally ill, he did a remarkable thing. He conceptualised an event from which it is possible to infer the interests and impact he had. With 


\section{Obituary}

the support of his department, he arranged a unique one-day programme of symposia for his colleagues. Or at least that is the way that it appeared. Panels of leading scholars would offer short statements on specified areas of research. Then Harry would comment on the statements, and the floor would be open for discussion. But the way Harry structured it, for each symposium there was a programme of required readings ahead of time to unify the symposium members' contributions; and there were study questions. On the appointed day, the discussions were intense. For the participants, it was like taking a second $\mathrm{PhD}$ in eight hours: Harry, of course, acted as the graduate teacher of everyone present, including some of the most eminent historians in the world.

The programme started out with 'Networks, Practices, \& Latour', aimed at the forms in which scientific and technological ideas are formulated and communicated. Nuances of every kind came out - failed networks, repertoires of values, elements that undergirded networks (both epistemologies and personalities are necessary, Harry pointed out). Of course, in Harry's presence, everyone was aware of economics and politics on a variety of levels.

The next session was 'Standardisation and the Local', which provided further openings in which to plumb complexities. Standardisation took many forms - technology, records, protocols, procedures, values. The process could be international, with difficulties of translation, but always there were local variations, to an extent which confused policymakers and later historians. Harry then asked further consideration - about which populations could afford standards, on the one hand, and, on the other, how professionals use standards to re-make themselves.

'History and the Normative' then opened up a further dimension of underlying assumptions in science and medicine, those involving ethics and, again, epistemology. Harry, in his comments, turned to institutional settings, laboratories and clinics, and then addressed the acute questions of how people use statistical evidence, and the relation of the normative to inequality of people.

The conference closed with a question always present in Harry's mind, 'Medical Marketplaces'. Economics was not just an abstract factor for him. He often revealed his belief that material motives affected the behaviour of scientists and physicians. Moreover, he maintained a consistent anti-commercial bias as he viewed events in the past, whether in the eighteenth century or the twentieth. At some periods in his life, it was more prominent than at other times, but it was always part of Harry.

Altogether, the 'Harryfest' conference, as it came to be called, suggests the intellectual sites and approaches that Marks affected so deeply in so many ways. In the formalities around the symposium, it was stated that Harry was hired originally at Hopkins explicitly to improve the intellectual climate. But over the years, he also did the job for all of the history of medicine. More than most humans, Harry Marks achieved an immediate immortality. His standards for quality and breadth in scholarship live on in the professional memories and identities of a generation of medical historians.

John C. Burnham,

Ohio State University 